\title{
Recruiting And Retaining A Diverse Faculty
}

James R. Lumpkin, (E-mail: james.lumpkin@okstate.edu), Oklahoma State University

\begin{abstract}
( $t$ is not news that American universities are not well diversified (e.g., Trower 2002, Antonio 2003). A quick look at your own faculty list will probably corroborate the literature. Much has been written not only on the need for a diverse faculty, but also the beneficial relationship between a diverse student body and a diverse faculty. For example, Antonio (2003) suggests that having a diverse student body:
\end{abstract}

- $\quad$ Reduces isolation experienced by faculty of color;

- broadens the range of what is taught and how, and develops collaboration opportunities and sharing of ideas and pedagogies;

- $\quad$ reduces the possibility of denial of promotion and tenure because of race or ethnicity as the students may become activists; and

- $\quad$ reduces expectation placed on faculty to handle minority affairs as the university will more likely have formal programs and administration in place.

Student diversity and faculty diversity are mutually supportive, and both should be included in your diversity plan. With that said, the focus will now be on the seemingly more difficult task of recruiting and retaining a diverse faculty. While a diverse faculty should include females as well as people of color, the focus will be on faculty of color and specifically African-Americans, as that is where universities, in my opinion, tend to do the poorest job.

\section{RECRUITING A DIVERSE FACULTY}

A university often has two competing objectives.

- $\quad$ Finding the "best" candidate with respect to teaching and research or potential research and/or in a particular sub-field. Thus, the college must recruit only from schools with the best reputation.

- Desire for diversity when candidates may not be from top schools, even if they have solid credentials or when sub-fields don't match.

It is clear that a college cannot reduce the quality of the new hire (or the expectations after hiring). This would likely set the new faculty member up for failure. Perhaps there would be open resentment, but perhaps it would only appear subtly during periodic reviews or at tenure time. This possible situation will be exacerbated by the fact that most new hires create salary compression, if not inversion. The incremental salary that may be required to attract quality minority candidates will almost certainly create inversion. Perceived lesser quality coming in or requirements after the new faculty arrive, have the potential to make the situation untenable.

Failure of minority faculty to succeed will likely derail the efforts to attract and retain minority faculty. This is especially problematic at the early stages of a diversification effort when the faculty and the environment are being watched carefully and a track record has yet to be built. It is incumbent to make sure the first few hires are successful. This requires special effort and care in those initial recruiting efforts.

There is a general perception that there is a limited pool of faculty of color and that if they are identified, they are too expensive or have multiple offers and go only to the "top" schools. Although not all agree with this - see, for example, the excellent article by Smith (2000) - the perception is repeated so often that it is elevated to the level of truth and we must deal with the defeatist attitudes. 


\section{GROWING YOUR OWN}

One method to help overcome this situation is to develop your own pool. This requires identifying promising minority students and providing a mechanism for them to earn advanced degrees and ultimately return as faculty members. Some private schools have had success by providing financial support for students to earn the Ph.D. at another university with the agreement to return for a specified number of years and the hope of long-term employment. Public universities have a more difficult time providing that same financial support. However, doctoralgranting universities have an advantage over masters-only universities as they could utilize their own programs to "grow their own." The negative, of course, is that by hiring your own graduates, new ideas or experiences are not infused. That becomes a difficult hurdle for some existing faculty. An alternative is to help arrange post-docs for the candidate or visiting position while they complete the dissertation. The key is establishing these so the individual will be required to return to the university for a minimum period of time. That requirement generally would require some financial support - again problematic for public universities.

A modification of this idea is the creation of an alliance with peer doctoral-granting universities for a joint effort where the doctoral program itself is a joint one with shared courses and faculty and the student has experiences at multiple universities. This would create a pool of candidates with a rich experience base. Another similar approach is to have a reciprocal agreement with a set of peer schools much like U.S. schools exchanging students with foreign schools. Each sends students to the other for training on a quid pro quo basis.

For non-doctoral granting universities, alliances are still a viable route. Most doctoral programs are looking for outstanding new students and especially minority students. Sending your best students will help build a close relationship which will likely create the environment needed to bring those students back as new faculty.

\section{RECRUITING PROCESS}

If growing your own is not an option, how should you recruit faculty of color? First, the same process used for decades can not be continued. A special effort will be required along with a commitment from the top down. The dean must communicate to the departmental faculty the importance of diversity and obtain "buy in." That is, the important work must be done before even beginning the recruiting process.

Because the candidate pool is perceived to be small, a few specially placed ads will not be sufficient. Networking is required. The idea is to identify other universities with minority candidates and build a long-term relationship with them. The faculty should network with peers at other universities to identify potential candidates. As we know, the graduate faculty and major professors have tremendous influence on the universities students consider in their job search. Use those connections. This should be no different from the procedures used when looking for a senior faculty or, say, an endowed chair holder. Candidates are identified and pursued, rather than waiting for them to submit their applications. In this process, the college must guard against narrow thinking where only certain schools are considered - those we know and/or consider in our own image. Not all quality candidates attend these schools.

Once minority candidates have been identified, the next step is to successfully recruit them. While difficult, it is not impossible. The key, again, is breaking out of the normal recruiting mold. A typical campus visit would include:

- $\quad$ Showing the campus and college buildings;

- $\quad$ meeting the departmental faculty, the dean, and perhaps the provost;

- $\quad$ making a research presentation;

- $\quad$ taking them to eat at the best restaurant in town;

- $\quad$ having a faculty member drive them around town or possibly a brief real estate tour; and

- $\quad$ taking them back to the airport. 
All those things should certainly be done, but expand the visit to include aspects that may not be obvious but will likely be important to them and on which they will make a perceptual judgment. If, for example, an AfricanAmerican candidate is being recruited and the college is not sufficiently diverse in that area, arrange for visits with other African-American faculty across campus and in the community. They will be able to offer insight regarding such mundane but important things as social activities, churches, schools, housing, or even where to get their hair cut. Involve the university's diversity office and the top administration. They can provide invaluable insight from the university administration's view. That office should probably be your first contact in arranging meetings outside the college.

The goal in this special effort is not only to provide information that would not normally be needed for nonminority candidates, but to create a comfort level with the candidate. They have to know they will fit in and have the opportunities and social network they will need for support.

In urban areas, the candidate will likely just assume that this social network will be there, somewhere. For more rural universities, you must provide an opportunity for the candidate to see and explore these aspects; they may assume they are not available if they only see and interact with non-minorities.

\section{RETAINING A DIVERSE FACULTY}

Recruiting minority faculty is only part of the equation. Retaining the faculty also requires a special effort. They must be supported once they arrive and provided an opportunity to be successful. Moody (2004) notes that new minority hires should not be required to adhere to the existing culture, but rather the culture should be changed to assure that new hires are nurtured and supported and treated as valued colleagues. This nurturing and support must necessarily lead to tenure, which is often more important to minority faculty (Moody 2000). Towards that end, our standards must not be lessened or the notion of merit discarded. Instead, it must be ensured that the existing criteria are applied with a sufficiently broad perspective so that the faculty's contributions to the learning environment at the university, both in and outside the classroom, are fully and fairly taken into account (Alger 2000).

Too often there is what Turner and Myers (2000) call a "chilly climate" for faculty of color, even though we may not realize it. Among other factors, they cite:

- $\quad$ Having color or ethnicity given more attention than credentials;

- $\quad$ not receiving support or validation for research on minority issues;

- $\quad$ being expected to handle minority affairs; and

- $\quad$ having too few minorities on campus.

The culture that creates this "chilly climate," regardless how inadvertent, must be changed. This requires open discussion before the recruiting even begins. Waiting until the hire is completed to address these issues will likely guarantee a return to the comfort of business as usual. And, as usual, you will likely not be successful at either recruiting or retaining faculty of color.

Recruiting and retaining minority faculty is possible, but only if the administration and faculty commit to it and get out of their comfort zone. It is not going to happen by accident or without effort. Regardless of the approach you take, just start. The payoff can be significant! 


\section{REFERENCES}

1. Alger, Jonathan R. (2000), How to Recruit and Promote Faculty: Start by Playing Fair, Black Issues in Higher Education, Vol. 17 (20), 160-163.

2. Antonio, Anthony Licing (2003), Diverse Student Bodies, Diverse Faculties, Academe, Vol. 89 (6), 14.

3. Moody, JoAnn (2000), Tenure and Diversity: Some Different Voices, Academe, Vol. 86 (3), 30-34.

4. Moody, JoAnn (2004), Supporting Women and Minority Faculty, Academe, Vol. 90 (1), 47-52.

5. $\quad$ Smith, Daryl G. (2000), How to Diversify the Faculty, Academe, Vol. 86 (5), 48-53.

6. Trower, Cathy A. (2002), Why so Few Minority Faculty and What to Do? Connection: The Journal of the New England Board of Higher Education, Fall, 25-27.

7. Turner, C.S. and S.L. Myers (2000), Faculty of Color in Academe: Bittersweet Success, Needham Heights, MA: Allyn and Bacon.

\section{NOTES}

